Article

\title{
Phytochemical Composition and In Vitro Antimicrobial Activity of Essential Oils from the Lamiaceae Family against Streptococcus agalactiae and Candida albicans Biofilms
}

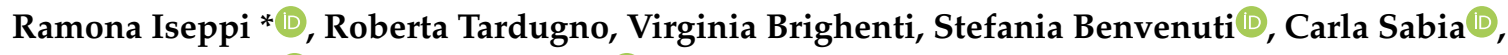 \\ Federica Pellati * (D) and Patrizia Messi \\ Department of Life Sciences, University of Modena and Reggio Emilia, Via G. Campi 103/287, \\ 41125 Modena, Italy; roberta.tardugno@gmail.com (R.T.); virginia.brighenti@unimore.it (V.B.); \\ stefania.benvenuti@unimore.it (S.B.); carla.sabia@unimore.it (C.S.); patrizia.messi@unimore.it (P.M.) \\ * Correspondence: ramona.iseppi@unimore.it (R.I.); federica.pellati@unimore.it (F.P.); \\ Tel.: +39-059-205-5795 (R.I.); +39-059-205-8565 (F.P.)
}

Received: 4 August 2020; Accepted: 7 September 2020; Published: 10 September 2020

\begin{abstract}
The antimicrobial activity of different essential oils (EOs) from the Lamiaceae family was evaluated on Streptococcus agalactiae, Candida albicans, and lactobacilli. S. agalactiae is the main cause of severe neonatal infections, such as sepsis, meningitis, and pneumonia. C. albicans is a primary causative agent of vulvovaginal candidiasis, a multifactorial infectious disease of the lower female reproductive tract. Lactobacilli represent the dominant bacterial species of the vaginal flora and constitute the natural defense against pathogens. On the basis of the preliminary results, the attention was focused on the EOs from Lavandula x intermedia Emeric ex Loisel. and Mentha arvensis L. By using gas ghromatography (GS) retention data and mass spectra, it was possible to identify more than $90 \%$ of the total composition of the EO samples. The minimal inhibitory concentration (MIC) and anti-biofilm activity of the two EOs were determined against all isolated strains, using the EOs by themselves or in combination with each other and with drugs (erythromycin and fluconazole). The results showed a good antimicrobial and anti-biofilm activity of both EOs and a synergistic effect, leading to the best results against all the strains, resulted using the combinations EOs/EOs and antimicrobials/EOs.
\end{abstract}

Keywords: essential oil; Lamiaceae; Lavandula x intermedia; Mentha arvensis; Streptococcus agalactiae; Candida albicans; antibiotics; synergic associations; anti-biofilm activity

\section{Introduction}

The vaginal flora is strongly related to women health. The vaginal ecosystem is typically dominated by different Lactobacillus species, mainly Lactobacillus crispatus, Lactobacillus gasseri, Lactobacillus iners, and Lactobacillus jensenii. They play a protective role by a combination of various mechanisms, i.e., by maintaining a low $\mathrm{pH}(<4.5)$, by a specific adhesion to the vaginal tissue, and by the production of inhibitory substances (e.g., organic acids, hydrogen peroxide, bacteriocins), thus reducing the development of most pathogenic microorganisms [1,2]. The lactobacilli reduction leads to an alteration of vaginal flora and, consequently, favors the pathogenic bacterial growth with health outcomes. Streptococcus agalactiae, also known as the Group B Streptococcus (GBS), is a Gram-positive, facultative anaerobe and an opportunistic pathogen for pregnant women, newborns, and elderly persons. GBS colonizes the female genital tract ( $50 \%$ of the female population), the gastrointestinal tract and the urethra of both men and women [3]. Between 10 and 30\% of pregnant women are intermittently or 
persistently colonized by GBS and they are at risk of transmitting this pathogen to their newborn infant in the perinatal period [4,5]. GBS can be life-threatening, when it is vertically transmitted through the birth canal from a colonized mother to her newborn at birth, causing pneumonia, meningitis, and sepsis.

The most accepted medical procedure for the detection of GBS in pregnant women is a maternal screening for clinical risk factors at delivery or rectovaginal colonization only at 35-37 weeks of gestation and, in the presence of this pathogen, a subsequent intrapartum antibiotic prophylaxis is prescribed [6]. With few exceptions, GBS remains fully susceptible to penicillin. However, about $10 \%$ of pregnant women are allergic to penicillin and an alternative to this antibiotic should be administered. Erythromycin and clindamycin are the most used treatments, but GBS has increased over time its resistance to these drugs [7].

Candida albicans is a normal constituent of human flora, and a common colonizer of mucosal membrane, skin, gastrointestinal tract, and vaginal mucosa. In more than $75 \%$ of cases, this species behaves as an opportunistic pathogen responsible for vulvovaginal candidiasis (VVC) [8-11]. The ability of Candida species to form biofilm is considered as a critical point in its pathogenesis, with an increased resistance to traditional antimycotic agents [9,12-14]. Fluconazole is the first-line antifungal agent used in clinical VVC infections [13]. However, variable sensitivity or resistance to this drug reduces the effectiveness of the treatment, thus inducing recurrent vaginal candidiasis [10,15-21].

This growing trend indicates that there is a crucial need for highly efficient antibacterial and antifungal alternative agents with few side effects. The vast structural diversity of natural compounds of plant origin provides a unique opportunity for discovering new bioactive molecules. In this ambit, essential oils (EOs) represent an alternative to conventional antimicrobial treatments, due to their broad-spectrum activity against microorganisms, mainly as a consequence of the alteration of the microbial membrane and cell wall, with resulting loss of cytoplasmic material. EOs biological activities are due to their complex chemical composition and presence of phenols, which are compounds of interest for the treatment of both bacterial and fungal infections [9,22-27].

In this work, different essential oils (EOs) belonging to the Lamiaceae family were evaluated for their antimicrobial activity against two S. agalactiae and two C. albicans strains isolated from vaginal swabs. Four Lactobacillus strains were also tested since, during women fertile age, they represent $90 \%$ of vaginal flora, and they play an important role in protecting the host from genital infections.

\section{Results}

\subsection{Agar Disk Diffusion Assay}

As shown in Table S1, erythromycin and fluconazole displayed their activity against Streptococcus agalactiae and Candida albicans strains, respectively. These two antimicrobials used as the reference showed their activity also towards lactobacilli. By using the agar disk diffusion method and considering the zone of inhibition, it was also possible to verify the EOs inhibitory activity against all the microorganisms tested. Among the EOs used, Lavandula $x$ intermedia Emeric and Mentha arvensis L. were the most active against all $C$. albicans strains, even if a less evident activity of M. arvensis EO towards the C. albicans 2 strain emerged. L. $x$ intermedia showed also a good antibacterial activity against S. agalactiae, in particular, towards S. agalactiae ATCC 13813. Satureja montana and Thymus vulgaris EOs displayed good activity against $S$. agalactiae, while their activity towards $C$. albicans strains was lower than L. $x$ intermedia and $M$. arvensis EOs. M. arvensis EO exhibited also antimicrobial activity against lactobacilli, if compared to L. $x$ intermedia EO. L. $x$ intermedia $\mathrm{EO}$ was selected for further chemical analysis, due to its excellent antimicrobial activity against $S$. agalactiae and C. albicans strains and its low activity towards lactobacilli. M. arvensis was chosen for its activity against candida, a microorganism found to be frequently resistant to fluconazole, the first-line antifungal agents used in clinical VVC infections, and often responsible for recurrent vaginal diseases. 


\subsection{Qualitative and Semi-Quantitative Analysis of EOs}

On the basis of the preliminary results obtained by the agar disk diffusion assay, a phytochemical characterization of L. $x$ intermedia and $M$. arvensis EOs was carried out by means of gas chromatography (GC). By using retention data, mass spectra, and data reported in the literature, it was possible to identify the analytes in all the EO samples (Table 1). More than $90 \%$ of the total composition for each EO was characterized.

Table 1. Qualitative and semi-quantitative analysis of Lavandula $x$ intermedia and Mentha arvensis essential oils (EOs). Data are expressed as \% relative peak area values \pm standard deviation (SD).

\begin{tabular}{|c|c|c|c|}
\hline Compound ${ }^{a}$ & $L R I^{\mathrm{b}}$ & Lavandula $x$ intermedia & Mentha arvensis \\
\hline$\alpha$-Thujene & 926 & $0.1^{\mathrm{c}}$ & - \\
\hline$\alpha$-Pinene & 931 & $0.7^{\mathrm{c}}$ & $0.7^{\mathrm{c}}$ \\
\hline Camphene & 946 & $0.5^{\mathrm{c}}$ & - \\
\hline Sabinene & 971 & $0.2^{\mathrm{c}}$ & $0.3^{c}$ \\
\hline$\beta$-Pinene & 974 & $0.5^{c}$ & $0.8^{\mathrm{c}}$ \\
\hline$\beta$-Myrcene & 990 & $1.0 \pm 0.1$ & $0.7^{\mathrm{c}}$ \\
\hline$p$-Cymene & 1024 & $0.3^{c}$ & - \\
\hline Limonene & 1027 & $1.4^{\mathrm{c}}$ & $3.6 \pm 0.1$ \\
\hline 1,8-Cineole & 1029 & $5.0^{\mathrm{c}}$ & $0.2^{\mathrm{c}}$ \\
\hline cis-Ocimene & 1037 & $0.8^{\mathrm{c}}$ & - \\
\hline trans-Ocimene & 1047 & $0.9^{\mathrm{c}}$ & - \\
\hline$\gamma$-Terpinene & 1058 & $0.1^{\mathrm{c}}$ & - \\
\hline Terpinolene & 1087 & $0.4^{\mathrm{c}}$ & - \\
\hline Linalool & 1100 & $36.0 \pm 0.1$ & $0.1^{\mathrm{c}}$ \\
\hline Camphor & 1143 & $5.9 \pm 0.1$ & - \\
\hline Isopulegol & 1146 & - & $0.8^{\mathrm{c}}$ \\
\hline Menthone & 1156 & - & $7.8 \pm 0.1$ \\
\hline Borneol & 1165 & $4.0^{\mathrm{c}}$ & - \\
\hline Isomenthone & 1167 & - & $5.4^{\mathrm{c}}$ \\
\hline Terpinen-4-ol & 1177 & $2.7^{\mathrm{c}}$ & - \\
\hline Menthol & 1180 & - & $73.8 \pm 0.2$ \\
\hline$\alpha$ - Terpineol & 1191 & $0.9^{c}$ & $0.1^{\mathrm{c}}$ \\
\hline Pulegone & 1245 & - & $0.5^{c}$ \\
\hline Piperitone & 1259 & - & $0.5^{\mathrm{c}}$ \\
\hline Linalyl acetate & 1263 & $27.3 \pm 0.2$ & - \\
\hline Lavandulyl acetate & 1293 & $1.8^{\mathrm{c}}$ & - \\
\hline Menthyl Acetate & 1297 & - & $2.1^{\mathrm{c}}$ \\
\hline$\beta$-Bourbonene & 1390 & - & $0.1^{\mathrm{c}}$ \\
\hline$\beta$-Caryophyllene & 1424 & $1.5^{\mathrm{c}}$ & $0.3^{c}$ \\
\hline Germacrene D & 1487 & - & $0.4^{\mathrm{c}}$ \\
\hline Caryophyllene oxide & 1592 & $0.2^{\mathrm{c}}$ & - \\
\hline Total & & 92.1 & 98.2 \\
\hline
\end{tabular}

L. $x$ intermedia EO showed a composition rich in linalool (36.0\%), linalyl acetate (27.3\%). Other peculiar constituents of this hybrid were camphor (5.9\%), 1,8-cineole (5.0\%), and borneol $(4.0 \%)$ [28,29]. M. arvensis EO main compounds included menthol (73.8\%), menthone (7.8\%), isomenthone $(5.4 \%)$, limonene $(3.6 \%)$, and menthyl acetate $(2.1 \%)$. The two EOs composition was in accordance with the data reported in the literature [30].

\subsection{Minimum Inhibitory Concentration (MIC)}

The minimum inhibitory concentrations (MICs) against all strains of both antimicrobials confirmed the results of the disk diffusion test (Table 2). As regards the EOs, the best antimicrobial activity was observed for L. $x$ intermedia $\mathrm{EO}$, with values ranging from 9 to $18 \mu \mathrm{g} / \mathrm{mL}$ against all S. agalactiae and 
C. albicans strains. M. arvensis EO, as already observed with the agar disk diffusion assay, resulted less active against all the pathogenic strains, with values ranging from 18 to $144 \mu \mathrm{g} / \mathrm{mL}$. On the contrary, higher MIC values were obtained for all the Lactobacillus strains treated with L. $x$ intermedia EO than with $M$. arvensis EO.

Table 2. Minimum inhibitory concentration (MIC) of EOs in comparison with the two reference antimicrobials (erythromycin and fluconazole). Data are expressed as $\mu \mathrm{g} / \mathrm{mL}$.

\begin{tabular}{ccccc}
\hline Strains & Lavandula x intermedia & Mentha arvensis & Erythromycin & Fluconazole \\
\hline Streptococcus agalactiae 1 & 18 & 36 & 2 & - \\
Streptococcus agalactiae 2 & 9 & 18 & 1 & - \\
Streptococcus agalactiae ATCC 13813 & 18 & 18 & 0.125 & - \\
Candida albicans 1 & 18 & 18 & - & 4 \\
Candida albicans 2 & 9 & 144 & - & 4 \\
Candida albicans ATCC 10231 & 18 & 72 & - & 0.25 \\
Lactobacillus spp.1 & 144 & 9 & 0.25 & 1 \\
Lactobacillus spp.2 & 144 & 18 & 0.25 & 1 \\
Lactobacillus spp.3 & 72 & 18 & 1 & 0.5 \\
Lactobacillus spp.4 & 72 & 18 & & \\
\hline
\end{tabular}

\subsection{Determination of the Fractional Inhibitory Concentration Index (FICI)}

The fractional inhibitory concentration (FIC) index evaluation indicated the absence of antagonistic effects and showed several synergistic interactions, in particular, between the two EOs against S. agalactiae and C. albicans strains (Table S2). Furthermore, it is important to underline the synergistic effect of the two EOs with erythromycin and fluconazole, even if less evident for the combination $M$. arvensis EO/erythromycin. The synergic combination as this could allow a decrease in the concentration of antimicrobial necessary for the therapeutic treatment.

\subsection{Time-Kill Studies}

The results of time-kill studies are shown in Figures 1 and 2. Both EOs were active against all S. agalactiae and C. albicans strains, even if L. $x$ intermedia EO was more effective than M. arvensis EO. A synergistic activity against $S$. agalactiae and $C$. albicans was observed with the combination antimicrobial/EO, and in particular when the two antimicrobials were used in association with L. $x$ intermedia EO. The synergistic activity also emerged with the combination EO/EO against all S. agalactiae and C. albicans test strains. Lastly, M. arvensis EO reduced the presence of lactobacilli more than L. $x$ intermedia EO. The anti-lactobacilli activity was detected with the synergic combination antibiotic/EO and EO/EO only for two Lactobacillus strains. Erythromycin and fluconazole activity against all tested strains confirmed the sensitivity patterns.


Figure 1. Cont. 

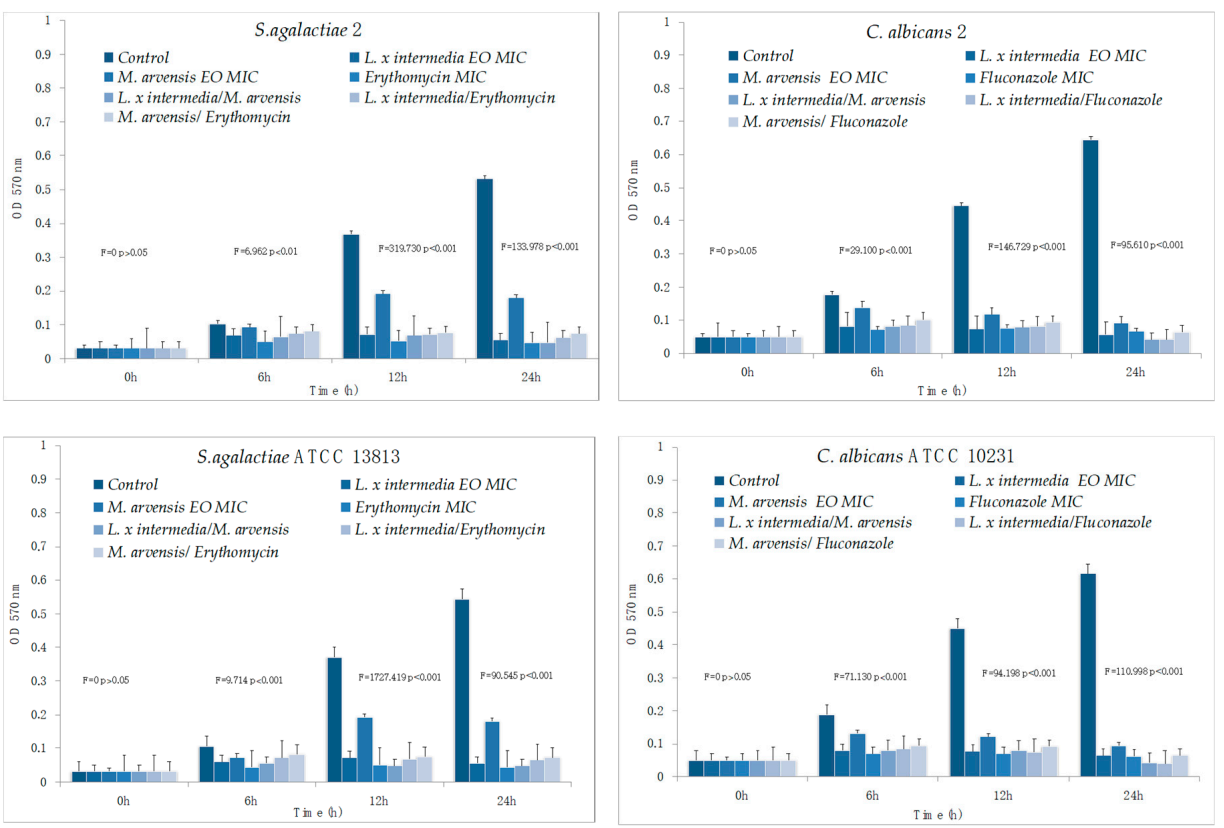

Figure 1. Time-kill studies of L. $x$ intermedia, M. arvensis EOs, antimicrobials (erythromycin and fluconazole) and of different combinations (antimicrobial/EO and EO/EO) against Streptococcus agalactiae and Candida albicans strains. $p$-values of $<0.05, p<0.01, p<0.001$ and $p<0.0001$ were considered significant by $t$-test and ANOVA.
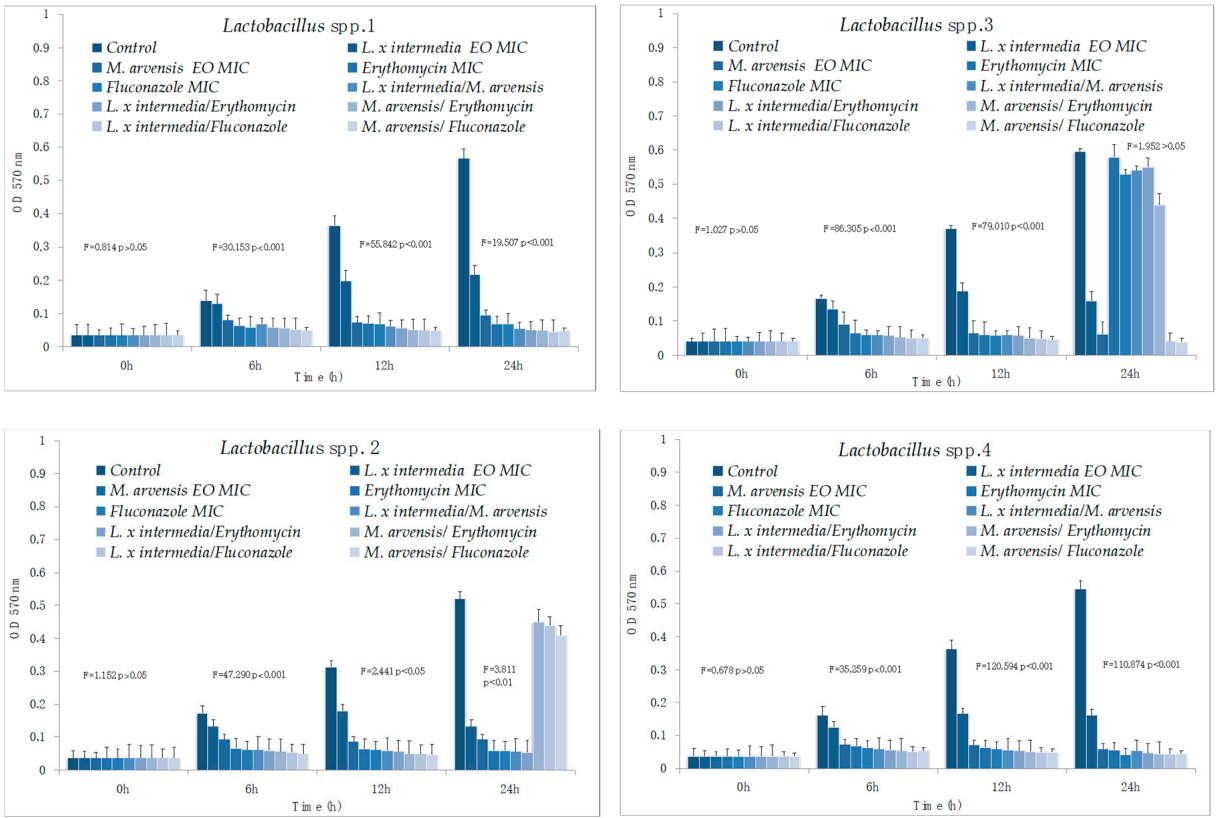

Figure 2. Time-kill studies of L. $x$ intermedia, M. arvensis EOs, antimicrobials (erythromycin and fluconazole), and of different combinations (antimicrobial/EO and EO/EO) against Lactobacillus spp. strains. $p$-values of $<0.05, p<0.01, p<0.001$ and $p<0.0001$ were considered significant by $t$-test and ANOVA.

\subsection{Anti-Biofilm Activity Determination}

Erythromycin and all the combinations (EO/EO and antibiotic/EO) were effective against the mature biofilm of $S$. agalactiae strains. The synergistic effect of the EOs used in combination resulted more evident against the ' $48 \mathrm{~h}$ old' mature biofilm and, for the single EO, with a significant difference with the control (range of $p$-value from 0.004112 to 0.001285 ). Concerning C. albicans strains, C. albicans 
2 and C. albicans ATCC 10231 in particular, fluconazole and the synergistic combinations (EO/EO and antifungal/EO) showed an excellent anti-biofilm activity. In the whole, L. $x$ intermedia EO exhibited a better activity than $M$. arvensis $\mathrm{EO}$ against both the ' $24 \mathrm{~h}$ and $48 \mathrm{~h}$ old' mature biofilm, proving to be the most effective product capable of counteracting its development (Figure 3).
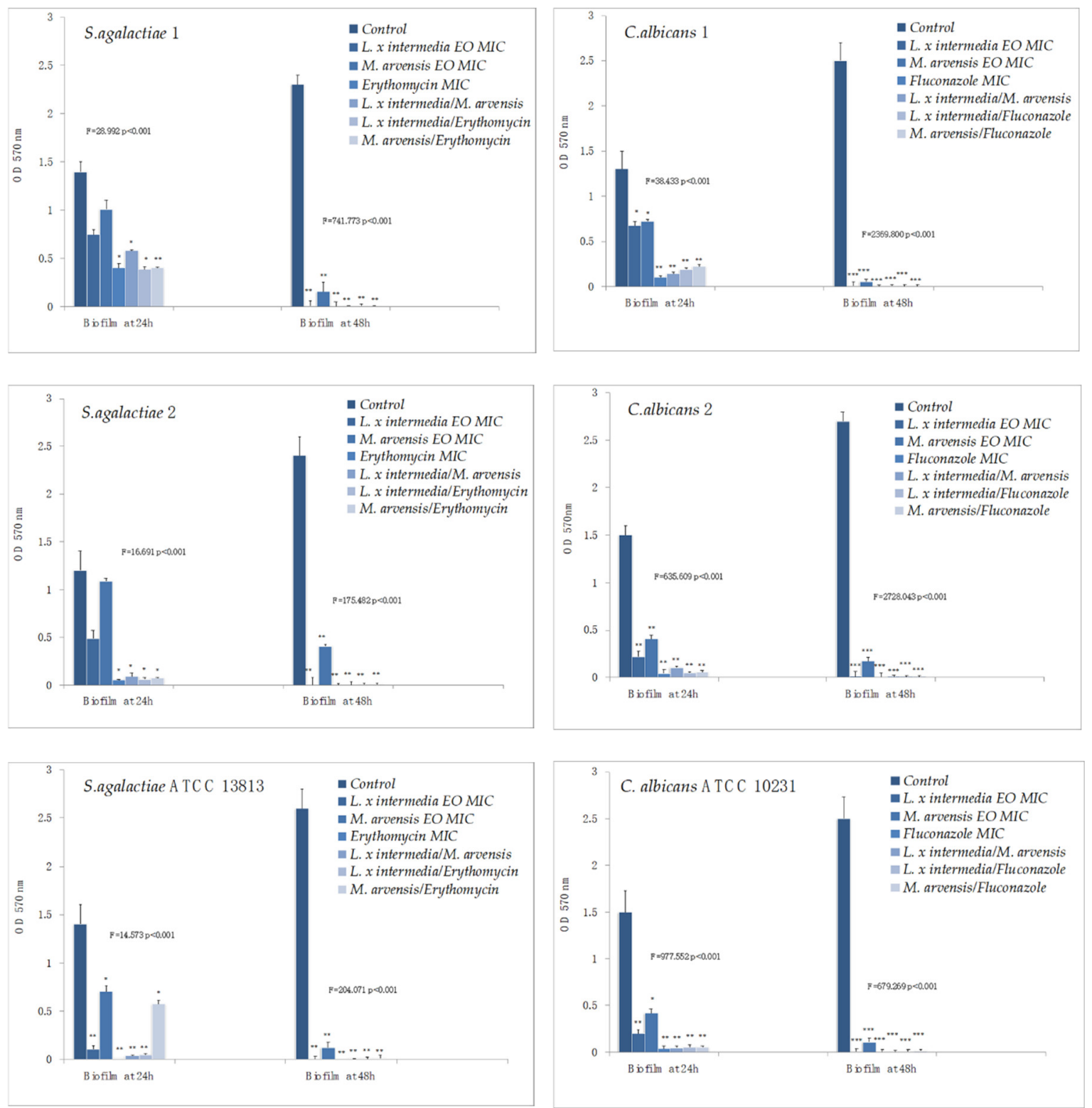

Figure 3. Anti-biofilm activity of L. $x$ intermedia, M. arvensis EOs, antimicrobials (erythromycin and fluconazole), and of different combinations (antimicrobial/EO and EO/EO) against S. agalactiae and C. albicans strains. Results were expressed in optical density (OD) $570 \mathrm{~nm}$ as the arithmetic mean of the three determinations. $p$-values of $<0.05\left(^{*}\right), p<0.01\left(^{* *}\right), p<0.001\left(^{* *}\right)$ were considered significant by $t$-test and ANOVA.

Lastly, L. $x$ intermedia EO did not exhibit a remarkable activity towards the ' $24 \mathrm{~h}$ and $48 \mathrm{~h}$ old' mature biofilm produced by Lactobacillus strains. Conversely, $M$. arvensis EO, fluconazole, and all the associations showed a good anti-biofilm activity against ' $24 \mathrm{~h}$ old' mature biofilm of the same ( $p$-value ranging from 0.0324 to 0.0041 ) (Figure 4). 



Figure 4. Anti-biofilm activity of L. x intermedia, M. arvensis EOs, antimicrobials (erythromycin and fluconazole), and of different combinations (antimicrobial/EO and EO/EO) against Lactobacillus spp. strains. Results were expressed in OD $570 \mathrm{~nm}$ as the arithmetic mean of the three determinations. $p$-values of $<0.05\left({ }^{*}\right), p<0.01\left({ }^{* *}\right), p<0.001\left(^{* * *}\right)$ and $p<0.0001\left(^{* * * *}\right)$ were considered significant by $t$-test and ANOVA.

\subsection{Quantification of EOs Activity on Mature Biofilm by Fluorescence Assay Study}

We investigated biofilm changes following single EOs and their combination treatments. The ' $24 \mathrm{~h}$ old' mature biofilm was treated either with the EOs alone or in combination (EO/EO and antimicrobial/EO) and then stained with CFDA and PI to define a numerical quantification of live and dead cells.

The EOs from L. $x$ intermedia and M. arvensis, as well as the combinations (EO/EO and antimicrobial/EO) strongly reduced the number of viable cells of all tested strains (Figures 5 and 6 ). L. $x$ intermedia $\mathrm{EO}$ was more active against $S$. agalactiae and $C$. albicans strains in comparison with $M$. arvensis EO. On the other hand, L. $x$ intermedia $\mathrm{EO}$ was less effective against all tested lactobacilli, as previously observed.

\subsection{Effectiveness of EOs Activity on Mature Biofilm by Fluorescence Microscopy Study}

The anti-biofilm activity was assessed against all tested strains, by using live/dead staining in association with the observation under a fluorescence microscope. After treatment with the EOs themselves and their combinations (EO/EO and antimicrobial/EO), an abundant red fluorescence indicating dead cells in the polymeric matrix of S. agalactiae, C. albicans, and lactobacilli biofilm was observed (Figure 7). With regard to these last strains, the presence of viable lactobacilli in the sample treated with L. $x$ intermedia $\mathrm{EO}$ once again indicates the reduced impact of this EO on the natural protective vaginal microflora. 

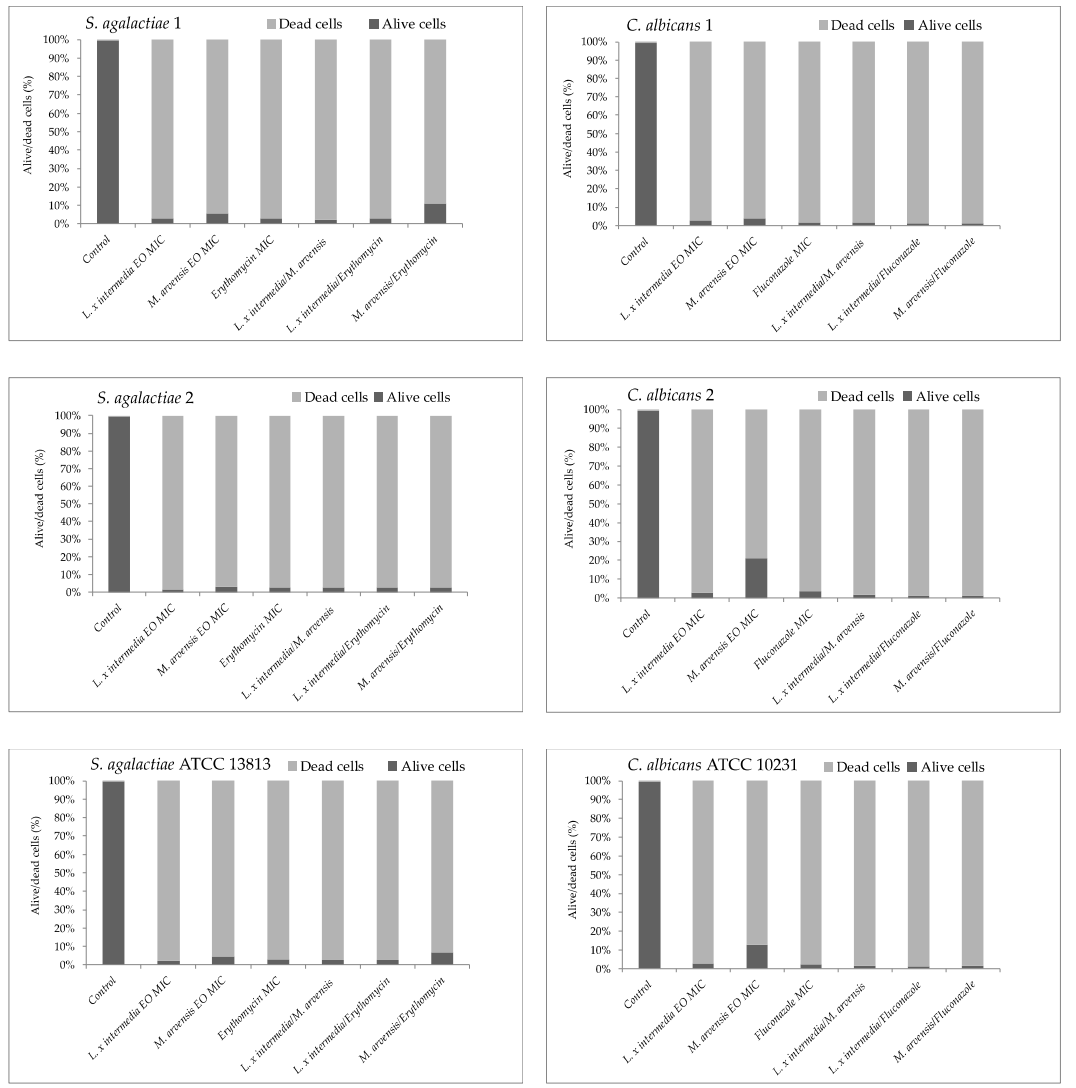

Figure 5. Quantification of alive/dead cells in the biofilm. Relative fluorescence units (RFU) mean of alive and dead cells into S. agalactiae and C. albicans biofilm, treated with L. $x$ intermedia and M. arvensis EOs, antimicrobials (erythromycin and fluconazole), and with different combinations (antimicrobial/EO and EO/EO). The data shown are representative of three determinations. Statistically significant difference between alive and dead cells $(p$-values $<0.05)$ was detected by Qui-square test.
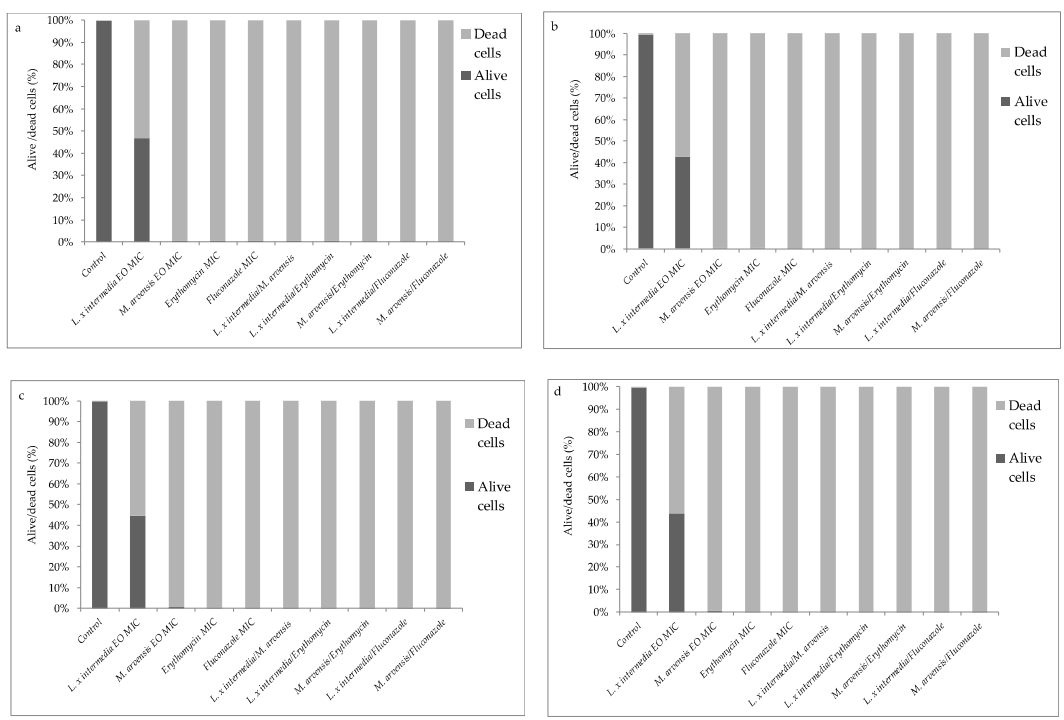

Figure 6. Quantification of alive/dead cells in the biofilm. Relative fluorescence units (RFU) mean of alive and dead cells into Lactobacillus spp. 1, Lactobacillus spp. 2, Lactobacillus spp. 3, and Lactobacillus spp. 4 ((a-d), respectively) biofilm, treated with L. $x$ intermedia and M. arvensis EOs, antimicrobials (erythromycin and fluconazole) and with different combinations (antimicrobial/EO and EO/EO). The data shown are representative of three determinations. Statistically significant difference between alive and dead cells $(p$-values $<0.05)$ was detected by Qui-square test. 

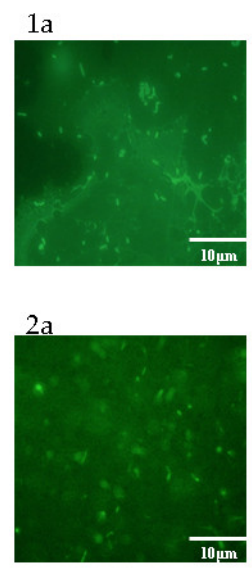

$3 a$

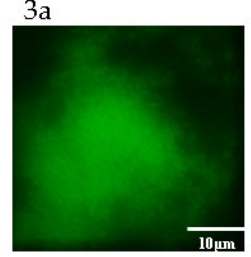

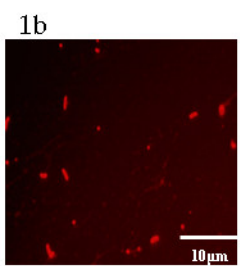

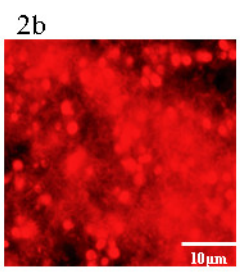

$3 \mathrm{~b}$

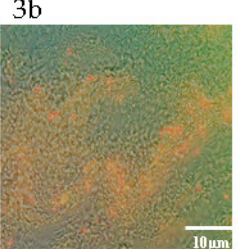

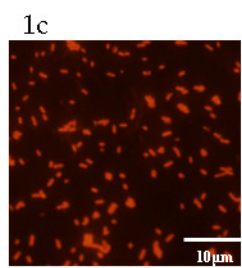

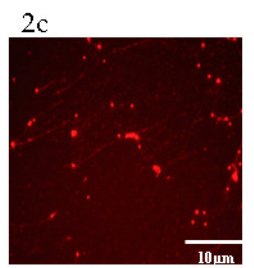

$3 c$



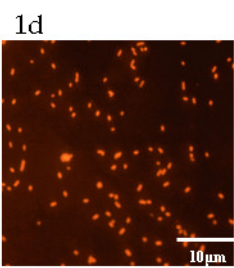
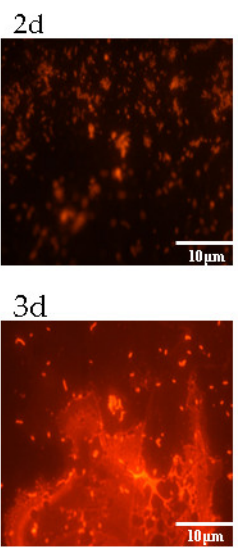

Figure 7. Images of light microscopy obtained by using "live/dead cells stain kit" for: S. agalactiae (1a), C. albicans (2a), and Lactobacillus spp. (3a) mature biofilm; S. agalactiae (1b), C. albicans (2b) and Lactobacillus spp. (3b) mature biofilm treated with L. x intermedia EO; S. agalactiae (1c), C. albicans (2c) and Lactobacillus spp. (3c) mature biofilm treated with M. arvensis EO; S. agalactiae (1d), C. albicans (2d) and Lactobacillus spp. (3d) mature biofilm treated with synergistic combination EO/EO. Green fluorescence labels live cells, whereas red fluorescence labels dead cells. The scale bars indicate $10 \mu \mathrm{m}$.

\section{Discussion}

EOs are widely used as a possible alternative therapy for their antimicrobial effects [31,32]. The screening of medical plants, and in particular of those rich in EOs, for antibacterial and antifungal activities is important to find new active antimicrobial compounds. Many studies on the antibacterial activity of Lavandula EOs have been based on Lavandula angustifolia Miller [29,33], even if other varieties, such L. x intermedia, have shown therapeutic potential [34]. Lavandula species have also demonstrated to be a weapon against antimicrobial resistant pathogens responsible for human infections [35-38]. Many studies have focused on the antibacterial effects of Lavandula volatile compounds, such as linalool, linalyl acetate, and terpinen-4-ol [39,40]. EOs from Mentha species have also been used as a folk medicine, due to their antibacterial and antifungal activities attributed to high levels of monoterpenes, including menthol and menthone [41-43]. M. arvensis, also known as wild mint or corn mint, is one species with a high content of menthol (80-95\%) [44].

In this study, two EOs (i.e., L. $x$ intermedia and M. arvensis) were selected from a panel of EOs belonging to the Lamiaceae family on the basis of their antimicrobial activity against $S$. agalactiae and C. albicans, vaginal colonizers, and opportunistic pathogens, respectively. S. agalactiae colonizes female genital tract and it is the main cause of neonatal diseases, being transmitted vertically from a colonized mother to her newborn at birth [3-5]. Candida vaginitis is a complicated disease with wide-reaching effects that are governed by fungal biology and host physiology and response [9].

The natural defense against infections in the vaginal tract includes microbial flora, such as lactobacilli, which are believed to interfere with pathogens [19]. Several clinical studies have highlighted an inverse correlation between the presence of Lactobacillus species and S. agalactiae in female vaginal tract $[45,46]$. Lactobacilli can be able to protect from Candida colonization and infection because of their capability to adhere and compete for vaginal mucosa adhesion sites [47].

In light of all the above, the chemical characterization as well as the antibacterial and antifungal activities of L. $x$ intermedia and M. arvensis EOs against S. agalactiae, C. albicans, and Lactobacillus species 
were assessed. The results clearly indicated that these EOs, having a high content of linalool and linalyl acetate for L. $x$ intermedia and menthol for M. arvensis, respectively, showed a good antimicrobial activity against the two vaginal pathogens, in planktonic and in biofilm forms, both individually and in association with each other and with drugs (erythromycin and fluconazole). As reported for other medical and aromatic plants belonging to the Lamiaceae family, the anti-biofilm activity of EOs may occur through the modulation of certain genes involved in adhesion, a feature essential for biofilm formation and pathogenesis of microorganisms [48].

Other authors have already described the antimicrobial activity of Lavandula and Mentha EOs against Candida albicans and S. agalactiae isolated from vaginal swabs [49]. In addition, Minooeianhaghighi et al. have demonstrated that Lavandula EO is able to inhibit C. albicans, also in association with other EOs. The antibacterial activity of Lavandula EO seems closely related to amount of 1,8-cineol [49]. The anti-candida activity of Mentha EO has been described by other authors [50]. Pietrella et al. have found an antifungal activity of Mentha EO against azole-resistant C. albicans strains [50]. The antibacterial activity of these EOs could be due to their ability to degrade membrane proteins and cell permeability. Regarding anti-biofilm formation, EOs are able to inhibit adhesion of bacterial cells at the first stage of biofilm formation, which might be due to their capability to inhibit the quorum sensing (QS) activity, that enables bacterial cells to have a multicellular behavior [51]. Further study of the anti-QS activity of EOs should be analyzed in detail.

The single EOs and their combinations exhibited antibacterial activity also towards lactobacilli. L. $x$ intermedia EO was the less active against lactobacilli, thus allowing the recognized protective function of lactic flora on vaginal mucosa. Therefore, this natural product could be used in the clinical field for the control of the pathogens, respecting the survival of lactobacilli. Nevertheless, further studies are needed, especially on the activity and toxicity of the EO constituents, that can be also responsible for undesirable effects, such as irritation, blushes, phototoxicity, sensitizations, which are still limiting their medicinal use.

\section{Materials and Methods}

\subsection{Chemicals and Reagents}

All reference standards used for GC analysis, chromatographic grade organic solvents, and reagents were purchased from Sigma-Aldrich (Milan, Italy).

\subsection{Essential Oils}

Authentic EOs samples from L. x intermedia, M. arvensis, Origanum vulgare L., Satureja montana L., and Thymus vulgaris L., all obtained by hydrodistillation, were kindly provided by Alchimia Natura srl (Modena, Italy). The samples were stored at low temperature $\left(+4{ }^{\circ} \mathrm{C}\right)$, protected from light and humidity, until required for chemical analysis.

\subsection{Microbial Strains}

All the strains were collected in June 2017 from the Provincial Laboratory of Clinical Microbiology 'S. Agostino-Estense' Hospital (Modena, Italy). Vaginal swabs of women aged between 25 to 40 were randomly selected. The C. albicans $(n=2, C$. albicans IP01 and C. albicans IP02) and S. agalactiae (GBS) ( $n=2$, S. agalactiae IP03 and $S$. agalactiae IP04) strains were isolated on CHROMID agar $\left(\right.$ CHROMID $^{\circledR}$ Candida ${ }^{\circledR}$ Candida, bioMérieux, Milan, Italy) and on group B Streptococcus differential agar $\left(\mathrm{CHROMID}^{\circledR}\right.$ Strepto B, bioMérieux, Milan, Italy), respectively. Four strains of lactobacilli (Lactobacillus spp. 1-IP04, Lactobacillus spp. 2-IP05, Lactobacillus spp. 3-IP06, and Lactobacillus spp. 4-IP07) were also isolated in Man-Rogosa Sharpe agar (MRS agar, bioMérieux, Milan, Italy).

All the isolates were confirmed by matrix-assisted laser desorption ionization (MALDI) time-of-flight mass spectrometry (TOF/MS). C. albicans ATCC 10231 and S. agalactiae ATCC 13813 were 
included as positive controls. All strains were maintained in the same media containing $20 \%(w / v)$ glycerol at $-80^{\circ} \mathrm{C}$ until use.

\subsection{Agar Disk Diffusion Assay}

The preliminary determination of the effectiveness of the above mentioned EOs against all the microorganisms was carried out by using the agar disk diffusion assay, according to the standard procedure of the Clinical and Laboratory Standards Institute [52]. Sterile disks of $6 \mathrm{~mm}$ in diameter, containing $10 \mu \mathrm{L}$ of each EO, were placed on Tryptic Soy Agar (TSA, Oxoid) plates, previously seeded with $100 \mu \mathrm{L}$ of $10^{6} \mathrm{CFU} / \mathrm{mL}$ of cell suspensions. Erythromycin $(15 \mu \mathrm{g})$ and fluconazole $(25 \mu \mathrm{g})$ discs were used as the positive controls. After incubation at $37^{\circ} \mathrm{C}$ for $24 \mathrm{~h}$, in anaerobic condition for GSB and lactobacilli strains, the antagonistic activity of the EOs was quantified by a clear zone of inhibition in the indicator lawn around the disks and the diameters in millimeters of these zones were measured [53].

\subsection{GC Analysis}

GC-MS analyses were performed on a 7890A gas chromatograph coupled with a 5975C network mass spectrometer (Agilent Technologies, Germany). Compounds were separated on an Agilent Technologies HP-5 MS cross-linked poly-5\% diphenyl-95\% dimethyl polysiloxane $(30 \mathrm{~m} \times 0.25 \mathrm{~mm}$ i.d., $0.25 \mu \mathrm{m}$ film thickness) capillary column. The column temperature was initially set at $45^{\circ} \mathrm{C}$, then increased at a rate of $2{ }^{\circ} \mathrm{C} / \mathrm{min}$ up to $100{ }^{\circ} \mathrm{C}$, then raised to $250{ }^{\circ} \mathrm{C}$ at a rate of $5^{\circ} \mathrm{C} / \mathrm{min}$ and finally held for $5 \mathrm{~min}$. The injection volume was $0.1 \mu \mathrm{L}$, with a split ratio 1:20. Helium was used as the carrier gas, at a flow rate of $0.7 \mathrm{~mL} / \mathrm{min}$. The injector, transfer line, and ion-source temperature were 250, 280, and $230^{\circ} \mathrm{C}$, respectively. MS detection was performed with electron ionization (EI) at $70 \mathrm{eV}$, operating in the full-scan acquisition mode in the $m / z$ range $40-400$. EOs were diluted 1:20 $(v / v)$ with $n$-hexane before GC-MS analysis.

GC analyses with flame ionization detector (FID) were carried out on a $7820 \mathrm{~A}$ from Technologies. Compounds were separated on an Agilent Technologies HP- 5 cross-linked poly-5\% diphenyl-95\% dimethyl polysiloxane ( $30 \mathrm{~m} \times 0.32 \mathrm{~mm}$ i.d., $0.25 \mu \mathrm{m}$ film thickness) capillary column. The temperature program was the same as described above. The injection volume was $0.1 \mu \mathrm{L}$ in the split mode 1:20. Helium was used as the carrier gas at a flow rate of $1.0 \mathrm{~mL} / \mathrm{min}$. The injector and detector temperature were set at 250 and $300{ }^{\circ} \mathrm{C}$, respectively. The EOs and the reference standards were diluted to $1: 20(\mathrm{v} / \mathrm{v})$ with n-hexane before GC-FID analysis. The analyses were performed in triplicate for each sample.

\subsection{Qualitative and Semi-Quantitative Analysis}

Compounds were identified by comparing the retention times of the chromatographic peaks with those of authentic reference standards run under the same conditions and by comparing the LRIs relative to $\mathrm{C}_{8}-\mathrm{C}_{40} n$-alkanes obtained on the HP- 5 column under the above-mentioned conditions with the literature [54]. Peak enrichment by co-injection with authentic reference compounds was also carried out. Comparison of the MS-fragmentation pattern of the target analytes with those of pure components was performed. A mass-spectrum database search was carried out by using the National Institute of Standards and Technology (NIST, Gaithersburg, MD, USA) mass-spectral database (version 2.0d, 2005).

Semi-quantification was calculated as the relative percentage amount of each analyte; in particular, the values were expressed as the percentage peak area relative to the total composition of each EO obtained by GC-FID analysis.

\subsection{Minimum Inhibitory Concentration (MIC)}

The MIC values of L. $x$ intermedia and $M$. arvensis EOs were determined against all microorganisms by means of a microwell dilution method. The test was performed in sterile 96-well microplates by dispensing into each well $95 \mu \mathrm{L}$ of nutrient broth and $5 \mu \mathrm{L}$ of cell suspensions, to final inoculums 
concentrations of $10^{6} \mathrm{CFU} / \mathrm{mL}$. Then, $100 \mu \mathrm{L}$ of EO serial dilutions were added to obtain concentrations ranging from 512 to $0.25 \mu \mathrm{g} / \mathrm{mL}$ [55]. The last well, containing $195 \mu \mathrm{L}$ of nutrient broth and $5 \mu \mathrm{L}$ of the test strains without EOs, was used as the negative control. The antibiotics erythromycin and fluconazole, diluted in nutrient broth with strains added, were used as the positive control. The plates were incubated at $37^{\circ} \mathrm{C}$ for $24 \mathrm{~h}$, mixed on a plate shaker at $300 \mathrm{rpm}$ for $20 \mathrm{~s}$, and the MIC was defined as the lowest concentration of the EOs that inhibited visible growth of the tested microorganisms after measuring the optical density (OD) at $570 \mathrm{~nm}$, using a microtiter plate reader. All the experiments were repeated three times.

\subsection{Determination of the Fractional Inhibitory Concentration Index (FICI)}

The checkerboard method was carried out in nutrient broth by using the microdilution method to obtain the FICI for the combined application of L. $x$ intermedia and M. arvensis EOs and the combined effects of EOs and antimicrobials against all test strains. FICI was calculated as follows: MIC of the combination of the EOs/MIC of the EO alone. EOs were combined at MIC + MIC, MIC + 1/2 MIC, MIC $+1 / 4 \mathrm{MIC}, \mathrm{MIC}+1 / 8 \mathrm{MIC}, 1 / 2 \mathrm{MIC}+1 / 2 \mathrm{MIC}, 1 / 2 \mathrm{MIC}+1 / 4 \mathrm{MIC}, 1 / 2 \mathrm{MIC}+1 / 8 \mathrm{MIC}, 1 / 4 \mathrm{MIC}+1 / 4$ MIC, $1 / 4 \mathrm{MIC}+1 / 8 \mathrm{MIC}$, and $1 / 8 \mathrm{MIC}+1 / 8 \mathrm{MIC}$. The results were considered as synergy (FIC $\leq 0.5)$, addition $(0.5 \leq$ FIC $\geq 1)$, indifference $(1 \leq$ FIC $\geq 4)$, and antagonism (FIC $>4)$ [22].

\subsection{Time-Kill Studies}

The growth of all the test strains in contact with the corresponding antimicrobial, with $L . x$ intermedia and $M$. arvensis EOs and with the different combinations of EO/EO and antimicrobial/EO was evaluated by calculating the change in the optical density of cells grown. In a 96-well sterile microplate, $90 \mu \mathrm{L}$ of sterile nutrient broth and $10 \mu \mathrm{L}$ of the strains were placed in each well from a stock, previously diluted to obtain a density of about $10^{5} \mathrm{CFU} / \mathrm{mL}$. Antimicrobials and EOs were added at different concentrations for each well, depending on the results obtained during the evaluation of the MIC and of the fractional inhibitory concentration index. The microplate was incubated at $37^{\circ} \mathrm{C}$ with an oscillating speed of $150 \mathrm{rpm}$, and the optical density (OD) was determined at $595 \mathrm{~nm}$ at predetermined time intervals $(0,6,12$ and $24 \mathrm{~h})$ of exposure, using an automatic micro plate reader (Tecan Sunrise $\left.{ }^{\mathrm{TM}}\right)$. The experiments were replicated three times.

\subsection{Anti-Biofilm Activity Determination}

The effect of both EOs, by themselves or in combination (EO/EO and antimicrobial/EO) was tested on '24 and $48 \mathrm{~h}$ old' pre-formed biofilm, obtained using 96-well polystyrene microtiter plates, added with approximately $10^{5} \mathrm{CFU} / \mathrm{mL}$ of single microbial strains and incubated at $37^{\circ} \mathrm{C}$. After biofilm formation, the medium was gently aspirated and plates were washed three times with a sterile phosphate-buffered saline solution (PBS, $\mathrm{pH} 7.2$ ) to remove planktonic bacteria, and the compounds were added at MIC concentration. Following an additional incubation for $24 \mathrm{~h}$ at $37^{\circ} \mathrm{C}$, the biofilm biomass was quantified according to the crystal violet staining method by Stepanovic et al. [56]. Absorbance values were measured at $570 \mathrm{~nm}$ using a microtiter plate reader.

\subsection{Quantification of EOs Activity on Mature Biofilm by Fluorescence Assay Study}

Wells containing mature ' $24 \mathrm{~h}$ old' biofilm performed as above were washed with PBS solution, and the EOs, by themselves or in combination (EO/EO and antimicrobial/EO), were added at MIC concentration. After $24 \mathrm{~h}$ incubation treated and untreated wells (control) were washed twice with sterile PBS and stained by the "live/dead cells stain kit" (Thermo Fisher Scientific, Waltham, MA, USA), according to manufacturer instructions. The method is based on the use of propidium iodide (PI) as marker of dead cells and 5(6)-carboxyfluorescein diacetate (cFDA) to detect alive cells. After incubation in the dark at $37^{\circ} \mathrm{C}$ for $30 \mathrm{~min}$, the samples were washed twice with PBS and, to numerically quantify the amount of live and died cells, the fluorescence emission (CFDA excitation/emission: 485/528; 
PI excitation/emission: 528/645) was analyzed using a multi-well fluorescence plate reader (Synergy HTX, BIOTEK, Winooski, VT, USA). The results were expressed as relative fluorescence units (RFU).

\subsection{Effectiveness of EOs Activity on Mature Biofilm by Fluorescence Microscopy Study}

The effect of EOs on mature biofilm formation was evaluated in a 96-well microtiter plate, as described above. Subsequently, each well was washed two times with PBS to remove the unbound cells. Biofilm was fixed for $30 \mathrm{~min}$ with PBS-buffered $4 \%$ paraformaldehyde, then the samples were washed twice with PBS, treated with Prolong Gold antifade (PLGAR) (Thermo Fisher Scientific, Walthan, MA, USA) and stained by the "live/dead cells stain kit" (Thermo Fisher Scientific, Waltham, MA, USA), according to manufacturer instructions. The method is based on the use of propidium iodide (PI) as marker of dead cells and 5(6)-carboxyfluorescein diacetate (cFDA) to detect alive cells. After incubation in the dark at room temperature for $30 \mathrm{~min}$, biofilm was visualized by epifluorescence microscopy Nikon Eclipse 90i imaging system, equipped with Normaski DIC optics (Nikon Instruments Inc., Melville, NY, USA). Samples were photographed with a DS-2Mv Nikon digital camera.

\subsection{Statistical Analysis}

Each experiment was replicated three times. The statistical significance was determined by $t$-test, Qui-square test, and ANOVA test. The $p$-values were considered to be significant at $\leq 0.05$.

\section{Conclusions}

In this study, L. $x$ intermedia and M. arvensis EOs were selected from an initial panel of samples belonging to the Lamiaceae family on the basis of their preliminary activity against S. agalactiae, C. albicans, and lactobacilli, and their chemical composition was evaluated. The antimicrobial activity of the two EOs by themselves and in combination against all strains both in planktonic and in biofilm form was assessed. In particular, the association $\mathrm{EO} / \mathrm{EO}$ and antimicrobial/EO gave interesting results. All of these findings represent an advantage in an attempt to overcome drug resistance emergency in a period like this, where even the most recent synthetic antimicrobial drugs are not enough effective against multidrug-resistant bacteria.

In conclusion, these two EOs possess potential health benefit, especially that from L. x intermedia, and they could be valuable in the pharmaceutical fields, such as in gynecology and obstetrics, for the treatment of various symptoms and pathological conditions, and also for preventive purposes in detergents for personal hygiene, ointments, creams and ovules.

Supplementary Materials: The following are available online at http://www.mdpi.com/2079-6382/9/9/592/s1, Table S1: Agar Well Disk diffusion assay of EOs and common antimicrobial drugs. The inhibition diameters were measured in mm, Table S2: Minimal inhibitory concentration (MIC) and synergistic effect (FIC-INDEX) between EOs and antimicrobials (erythromycin and fluconazole). Data are expressed as $\mu \mathrm{g} / \mathrm{mL}$.

Author Contributions: Conceptualization, R.I., R.T. and F.P.; methodology R.I., R.T., V.B., S.B. and F.P.; validation, R.I., C.S. and F.P.; investigation, R.I., R.T. and V.B.; resources, C.S., S.B., F.P. and P.M.; data curation R.I., R.T., S.B., F.P. and P.M.; writing—original draft preparation R.I. and R.T.; writing—review and editing, C.S., S.B., F.P. and P.M.; visualization, R.I. and R.T.; supervision, S.B., F.P. and P.M.; project administration, S.B., F.P. and P.M.; funding acquisition, S.B., F.P. and P.M. All authors have read and agreed to the published version of the manuscript.

Funding: This research received no external funding.

Conflicts of Interest: The authors declare no conflict of interest.

\section{References}

1. Sabia, C.; Anacarso, I.; Bergonzini, A.; Gargiulo, R.; Sarti, M.; Condò, C.; Messi, P.; de Niederhausern, S.; Iseppi, R.; Bondi, M. Detection and partial characterization of a bacteriocin-like substance produced by Lactobacillus fermentum CS57 isolated from human vaginal secretions. Anaerobe 2014, 26, 41-45. [CrossRef] [PubMed] 
2. Pendharkar, S.; Brandsborg, E.; Hammarström, L.; Marcotte, H.; Larsson, P.G. Vaginal colonisation by probiotic lactobacilli and clinical outcome in women conventionally treated for bacterial vaginosis and yeast infection. BMC Infect. Dis. 2015, 15, 255. [CrossRef] [PubMed]

3. Kumherová, M.; Veselá, K.; Kosová, M.; Mašata, J.; Horáčková, Š.; Šmidrkal, J. Novel Potential Probiotic Lactobacilli for Prevention and Treatment of Vulvovaginal Infections. Probiotics Antimicrob. Proteins 2020. [CrossRef]

4. Johri, A.K.; Lata, H.; Yadav, P.; Dua, M.; Yang, Y.; Xu, X.; Homma, A.; Barocchi, M.A.; Bottomley, M.J.; Saul, A.; et al. Epidemiology of Group B Streptococcus in developing countries. Vaccine 2013, 31S, D43-D45. [CrossRef]

5. Clifford, V.; Garland, S.M.; Grimwood, K. Prevention of neonatal group B Streptococcus disease in the 21st century. J. Paediatr. Child Health 2012, 48, 808-815. [CrossRef] [PubMed]

6. Madrid, L.; Seale, A.C.; Kohli-Lynch, M.; Edmond, K.M.; Lawn, J.E.; Heath, P.T.; Madhi, S.A.; Baker, C.J.; Bartlett, L.; Cutland, C.; et al. Infant GBS Disease Investigator Group. Infant Group B Streptococcal Disease Incidence and Serotypes Worldwide: Systematic Review and Meta-analyses. Clin. Infect. Dis. 2017, 65, S160-S172. [CrossRef]

7. Nan, C.; Dangor, Z.; Cutland, C.L.; Edwards, M.S.; Madhi, S.A.; Cunnington, M.C. Maternal group B Streptococcus-related stillbirth: A systematic review. BJOG 2015, 122, 1437-1445. [CrossRef]

8. Mukesi, M.; Iweriebor, B.; Obi, L.C.; Nwodo, U.U.; Moyo, S.R.; Okoh, A. The activity of commercial antimicrobials, and essential oils and ethanolic extracts of Olea europaea on Streptococcus agalactiae isolated from pregnant women. BMC Complement Altern. Med. 2019, 19, 34. [CrossRef]

9. Sobel, J.D. Vulvovaginal candidosis. Lancet 2007, 369, 1961-1971. [CrossRef]

10. Abd Ellaha, N.H.; Abdel-Aleem, J.A.; Abdo, M.N.; Abou-Ghadir, O.F.; Zahran, K.M.; Hetta, H.F. Efficacy of ketoconazole gel-flakes in treatment of vaginal candidiasis: Formulation, in vitro and clinical evaluation. Int. J. Pharm. 2019, 567, 118472. [CrossRef]

11. Giordani, B.; Basnet, P.; Mishchenko, E.; Luppi, B.; Škalko-Basnet, N. Utilizing liposomal quercetin and gallic acid in localized treatment of vaginal Candida infections. Pharmaceutics 2020, 12, 9. [CrossRef] [PubMed]

12. Willems, H.M.E.; Ahmed, S.S.; Liu, J.; Xu, Z.; Brian, M.; Peters, B.M. Vulvovaginal candidiasis: A current understanding and burning questions. J. Fungi 2020, 6, 27. [CrossRef] [PubMed]

13. Hawser, S.P.; Douglas, L.J. Resistance of Candida albicans biofilms to antifungal agents in vitro. Antimicrob. Agents Chemother. 1995, 39, 2128-2131. [CrossRef] [PubMed]

14. Taff, H.T.; Mitchell, K.F.; Edward, J.A.; Andes, D.R. Mechanisms of Candida biofilm drug resistance. Future Microbiol. 2013, 8, 1325-1337. [CrossRef] [PubMed]

15. Zarnowski, R.; Sanchez, H.; Covelli, A.S.; Dominguez, E.; Jaromin, A.; Bernhardt, J.; Mitchell, K.F.; Heiss, C.; Azadi, P.; Mitchell, A.; et al. Candida albicans biofilm-induced vesicles confer drug resistance through matrix biogenesis. PLoS Biol. 2018, 16, e2006872. [CrossRef]

16. Ben-Ami, R. Treatment of Invasive Candidiasis: A Narrative Review. J. Fungi 2018, 4, 97. [CrossRef]

17. Harriott, M.M.; Lilly, E.A.; Rodriguez, T.E.; Fidel, P.L.; Noverr, M.C. Candida albicans forms biofilms on the vaginal mucosa. Microbiology 2010, 156, 3635-3644. [CrossRef]

18. Cai, Y.M.; Chen, X.S. Concerns regarding bias in estimates of recurrent vulvovaginal candidiasis. Lancet Infect. Dis. 2018, 18, 1180. [CrossRef]

19. Denning, D.W.; Kneale, M.; Sobel, J.D.; Rautemaa-Richardson, R. Global burden of recurrent vulvovaginal candidiasis: A systematic review. Lancet Infect. Dis. 2018, 18, e339-e347. [CrossRef]

20. Russo, R.; Superti, F.; Karadja, E.; De Seta, F. Randomised clinical trial in women with recurrent vulvovaginal candidiasis: Efficacy of probiotics and lactoferrin as maintenance treatment. Mycoses 2019, 62, 328-335. [CrossRef] [PubMed]

21. Donders, G.G.; Grienceviciene, S.; Ruban, K.; Bellen, G. Vaginal pH and microbiota during fluconazole maintenance treatment for recurrent vulvovaginal candidosis (RVVC). Diagn. Microbiol. Infect. Dis. 2020, 97, 115024. [CrossRef] [PubMed]

22. Hemaiswaryaa, S.; Kruthiventib, A.K.; Doblea, M. Synergism between natural products and antibiotics against infectious diseases. Phytomedicine 2008, 15, 639-652. [CrossRef] [PubMed]

23. Kon, K.V.; Rai, M.K. Plant essential oils and their constituents in coping with multidrug-resistant bacteria. Expert Rev. Anti-Infect. Ther. 2012, 10, 775-790. [CrossRef] [PubMed]

24. Raut, J.S.; Shinde, R.B.; Chauhan, N.M.; Karuppayil, S.M. Phenylpropanoids of plant origin as inhibitors of biofilm formation by Candida albicans. J. Microbiol. Biotechnol. 2014, 24, 1216-1225. [CrossRef] 
25. Karapandzova, M.; Stefkova, G.; Cvetkovikj, I.; Trajkovska-Dokik, E.; Kaftandzieva, A.; Kulevanova, S. Chemical composition and antimicrobial activity of the essential oils of Pinus peuce (Pinaceae) growing wild in R. Macedonia. Nat. Prod. Commun. 2014, 9, 1623-1628. [CrossRef]

26. Ennigrou, A.; Casabianca, H.; Vulliet, E.; Hanchi, B.; Hosni, K. Assessing the fatty acid, essential oil composition, their radical scavenging and antibacterial activities of Schinus terebinthifolius Raddi leaves and twigs. J. Food Sci. Technol. 2018, 55, 1582-1590. [CrossRef]

27. Carbone, C.; Teixeira, M.D.C.; Sousa, M.D.C.; Martins-Gomes, C.; Silva, A.M.; Souto, E.M.B.; Musumeci, T. Clotrimazole-Loaded Mediterranean Essential Oils NLC: A Synergic Treatment of Candida Skin Infections. Pharmaceutics 2019, 11, 231. [CrossRef]

28. Maietti, S.; Rossi, D.; Guerrini, A.; Useli, C.; Romagnoli, C.; Poli, F.; Bruni, R.; Sacchetti, G. A multivariate analysis approach to the study of chemical and functional properties of chemo-diverse plant derivatives: Lavender essential oils. Flavour Fragr. J. 2013, 28, 144-154. [CrossRef]

29. Tardugno, R.; Serio, A.; Pellati, F.; D’ Amato, S.; López, C.C.; Bellardi, M.G.; Di Vito, M.; Savini, V.; Paparella, A.; Benvenuti, S. Lavandula $x$ intermedia and Lavandula angustifolia essential oils: Phytochemical composition and antimicrobial activity against foodborne pathogens. Nat. Prod. Res. 2019, 33, 3330-3335. [CrossRef]

30. Tardugno, R.; Pellati, F.; Iseppi, R.; Bondi, M.; Bruzzesi, G.; Benvenuti, S. Phytochemical composition and in vitro screening of the antimicrobial activity of essential oils on oral pathogenic bacteria. Nat. Prod. Res. 2018, 32, 544-551. [CrossRef]

31. Bogavac, M.; Karaman, M.; Janjušević, L.J.; Sudji, J.; Radovanović, B.; Novaković, Z.; Simeunović, J.; Božin, B. Alternative treatment of vaginal infections-In vitro antimicrobial and toxic effects of Coriandrum sativum $\mathrm{L}$. and Thymus vulgaris L. essential oils. J. Appl. Microbiol. 2015, 119, 697-710. [CrossRef]

32. Bogavac, M.A.; Karaman, M.A.; Sudi, J.J.; Radovanović, B.B.; Janjušević, L.N.; Ćetković, N.B.; Tešanović, K.D. Antimicrobial potential of Rosmarinus officinalis commercial essential oil in the treatment of vaginal infections in pregnant women. Nat. Prod. Commun. 2017, 12, 127-130. [CrossRef] [PubMed]

33. Denner, S.S. Lavandula angustifolia Miller: English lavender. Holist. Nurs. Pract. 2009, 23, 57-64. [CrossRef]

34. Bajalan, I.; Rouzbahani, R.; Pirbalouti, A.G.; Maggi, F. Chemical composition and Antibacterial activity of iranian Lavandula $x$ hybrida. Chem. Biodivers. 2017, 14, e1700064. [CrossRef] [PubMed]

35. Haba, E.; Bouhdid, S.; Torrego-Solana, N.; Marqués, A.M.; Espuny, M.J.; García-Celma, M.J.; Manresa, A. Rhamnolipids as emulsifying agents for essential oil formulations: Antimicrobial effect against Candida albicans and methicillin-resistant Staphylococcus aureus. Int. J. Pharm. 2014, 476, 134-141. [CrossRef]

36. Sienkiewicz, M.; Głowacka, A.; Kowalczyk, E.; Wiktorowska-Owczarek, A.; Jóźwiak-Bębenista, M.; Łysakowska, M. The biological activities of cinnamon, geranium and lavender essential oils. Molecules 2014, 19, 20929-20940. [CrossRef]

37. Ait Said, L.; Zahlane, K.; Ghalbane, I.; El Messoussi, S.; Romane, A.; Cavaleiro, C.; Salgueiro, L. Chemical composition and antibacterial activity of Lavandula coronopifolia essential oil against antibiotic-resistant bacteria. Nat. Prod. Res. 2015, 29, 582-585. [CrossRef] [PubMed]

38. Karpiński, T.M. Essential oils of Lamiaceae family plants as antifungals. Biomolecules 2020, 10, 103. [CrossRef]

39. De Rapper, S.; Viljoen, A.; van Vuuren, S. The in vitro antimicrobial effects of Lavandula angustifolia essential oil in combination with conventional antimicrobial agents. Evid. -Based Complement. Alternat. Med. 2016, 2016, 2752739. [CrossRef] [PubMed]

40. Garzoli, S.; Turchett, I.G.; Giacomello, P.; Tiezzi, A.; Laghezza Masci, V.; Ovidi, E. Liquid and vapour phase of Lavandin (Lavandula $x$ intermedia) essential oil: Chemical composition and antimicrobial activity. Molecules 2019, 24, 2701. [CrossRef] [PubMed]

41. Imai, H.; Osawa, K.; Yasuda, H.; Hamashima, H.; Arai, T.; Sasatsu, M. Inhibition by the essential oils of peppermint and spearmint of the growth of pathogenic bacteria. Microbios 2001, 106, 31-39.

42. Ludwiczuk, A.; Kieltyka-Dadasiewiczb, A.; Sawicki, R.; Golusd, J.; Ginalskad, G. Essential Oils of some Mentha species and cultivars, their chemistry and bacteriostatic activity. Nat. Prod. Commun. 2016, 11, 1015-1018. [CrossRef] [PubMed]

43. Heydari, M.; Zanfardino, A.; Taleei, A.; Hadian, J.; Maresca, V.; Sorbo, S.; Di Napoli, M.; Varcamonti, M.; Basile, A.; Rigano, D.; et al. Effect of heat stress on yield, monoterpene content and antibacterial activity of essential oils of Mentha x piperita var. Mitcham and Mentha arvensis var. piperascens. Molecules 2018, 23, 1903. [CrossRef] [PubMed] 
44. Bose, S.K.; Yadav, R.K.; Mishra, S.; Sangwan, R.S.; Singh, A.K.; Mishra, B.; Srivastava, A.K.; Sangwan, N.S. Effect of gibberellic acid and calliterpenone on plant growth attributes, trichomes, essential oil biosynthesis and pathway gene expression in differential manner in Mentha arvensis L. Plant Physiol. Biochem. 2013, 66, 150-158. [CrossRef] [PubMed]

45. Kubota, T.; Nojima, M.; Itoh, S. Vaginal bacterial flora of pregnant women colonized with group B Streptococcus. J. Infect. Chemother. 2002, 8, 326-330. [CrossRef] [PubMed]

46. Ronnqvist, P.D.; Forsgren-Brusk, U.B.; Grahn-Hakansson, E.E. Lactobacilli in the female genital tract in relation to other genital microbes and vaginal $\mathrm{pH}$. Acta Obstet. Gynecol Scand. 2006, 85, 726-735. [CrossRef]

47. Parolin, C.; Marangoni, A.; Laghi, L.; Foschi, C.; Nahui Palomino, R.A.; Calonghi, N.; Cevenini, R.; Vitali, B. Isolation of vaginal Lactobacilli and characterization of anti-Candida activity. PLoS ONE 2015, 10, e0131220. [CrossRef]

48. Benzaid, C.; Belmadani, A.; Djeribi, R.; Rouabhia, M. The effects of Mentha piperita essential oil on C. albicans growth, transition, biofilm formation, and the expression of secreted aspartyl proteinases genes. Antibiotics 2019, 8, 10. [CrossRef]

49. Minooeianhaghighi, M.H.; Sepehrian, L.; Shokri, H. Antifungal effects of Lavandula binaludensis and Cuminum cyminum essential oils against Candida albicans strains isolated from patients with recurrent vulvovaginal candidiasis. J. Mycol. Med. 2017, 27, 65-71. [CrossRef]

50. Pietrella, D.; Angiolella, L.; Vavala, E.; Rachini, A.; Mondello, F.; Ragno, R.; Bistoni, F.; Vecchiarelli, A. Beneficial effect of Mentha suaveolens essential oil in the treatment of vaginal candidiasis assessed by real-time monitoring of infection. BMC Complement Altern. Med. 2011, 11, 18. [CrossRef]

51. Camele, I.; Elshafie, H.S.; Caputo, L.; De Feo, V. Anti-quorum sensing and antimicrobial effect of mediterranean plant essential oils against phytopathogenic bacteria. Front. Microbiol. 2019, 10, 2619. [CrossRef] [PubMed]

52. CLSI. Performance Standards for Antimicrobial Disk Susceptibility Tests: Approved Standard, 11th ed.; CLSI document M02eA11; Clinical and Laboratory Standards Institute: Wayne, PA, USA, 2012.

53. Klancnik, A.; Piskernik, S.; Jersek, B.; Mozina, S.S. Evaluation of diffusion and dilution methods to determine the antibacterial activity of plant extracts. J. Microbiol. Methods 2010, 81, 121-126. [CrossRef] [PubMed]

54. Adams, R.P. Identification of Essential Oil Components by Gas Chromatography/Mass Spectrometry, 4th ed.; Allured Publishing: Carol Stream, IL, USA, 2007.

55. Şahin, F.; Güllüce, M.; Daferera, D.; Sökmen, A.; Sökmen, M.; Polissiou, M.; Agar, G.; Özer, H. Biological activities of the essential oils and methanol extract of Origanum vulgare ssp. vulgare in the Eastern Anatolia region of Turkey. Food Control. 2004, 15, 549-557.

56. Stepanovic, S.; Vukovic, D.; Hola, V.; Di Bona Ventura, G.; Djukic, S.; Irkovic, I.C.; Ruzicka, F. Quantification of biofilm in microtiter plates: Overview of testing conditions and practical recommendations for assessment of biofilm production by staphylococci. APMIS 2007, 115, 891-899. [CrossRef] 